\title{
Network Analysis of Immigrants' Social Interaction in Diaspora. A Case Study of Zimbabweans at University of Fort Hare Alice Campus South Africa
}

\section{Lungisani Moyo}

\author{
Department of Communication, University of Fort Hare, Private Bag X 1314, Alice 5700
}

Email:lungie06@gmail.com

Limukani Mathe

Department of Communication, University of Fort Hare, Private Bag X 1314, Alice 5700

Email:limukanimathe@yahoo.com

Doi:10.5901/mjss.2014.v5n23p1541

\begin{abstract}
Zimbabwean students 'populace at the University of Fort Hare consists of the Shona, Ndebele, Kalanga, Nambya, Tonga, Shangani and Venda. However, Shona speaking students are the majority. The Ndebele- Shona relations are cordial due to the factors such as academic interactions, church relations, drinking and partying relations and some other factors related to the University context of communication. Ndebele- Shona trouble relations are minimised by academics, hostel relations, church relations found at University of Fort Hare. The fact that many Zimbabweans are sponsored by one sponsor (the Zimbabwean Presidential Scholarship) means that, they share common financial and academic challenges. However some of the NdebeleShona differences remain buried and unattended. Some of the Ndebele associate better with South Africans rather than their fellow Zimbabwean- Shona speaking people. The cause being that communication between a Shona and Ndebele is still problematic because most of the Shona cannot speak Ndebele, yet the Ndebele can speak Shona. Some of the Ndebele mentioned that Shona people do not want to learn the Ndebele language yet they (the Shona) want the Ndebele to speak their language.
\end{abstract}

Keywords: Zimbabwean students, Shona - Ndebele relations, Diaspora, Shonalised, Ndebelelised

\section{Introduction}

Zimbabwe consists of many languages approximately 16 official languages. These languages are English, Shona, Ndebele, Nambya, Tonga, Kalanga, Ndau, Koisan, Xhosa, Shangani, Venda Sotho, Tswana, Xhosa and Chewa. However English, Shona and Ndebele are the widely spoken languages in the country. Statistically it is believed that $70 \%$ of the Zimbabwean population is Shona speaking people and Shona happens to be their mother language. The second largest population is Ndebele; which accounts for about $20 \%$ and speak Ndebele as their mother or first language. The remaining $10 \%$ is shared among the different and unpopular populace. To date in Zimbabwe, the given statistics have been officially approved and all official languages are now accepted in education though English, Shona and Ndebele are the dominant ones, (Constitution of Zimbabwe: 2013).

"The term 'Shona' was not in use before the $19^{\text {th }}$ century, instead, there existed a large region of broadly similar language beliefs and institution larger than present day Zimbabwe and stretching into different areas now South Africa, Zambia and Mozambique", (Raftopoulos and Mlambo, 2009: 2). Pointing out the fact that, today Shona is a commonly used term, unifying different dialects such as Korekore, Manyika, Zezuru, Karanga and Ndau. These dialects have common linguistics and fewer differences, of course. "The term Shona is a collective noun which conflates the linguistic, cultural and political attributes of a people who did not even know themselves by that name until the late 19th century", Raftopoulos and Mlambo, (2009: 3). Today more Shona speaking people occupy mainly Mashonaland, Midlands and Masvingo regions in Zimbabwe.

The Ndebele speaking people originated from the Nguni land now called South Africa. "In 1820, there was no Ndebele community until Mzilikazi Khumalo broke away from the Zulu Kingdom to construct such a community on his long journey to the north", (Zewde, 2008:174). They were known as the Khumalo before Sotho people identified them as the 'Matebele'. Today, Ndebele speaking groups are mostly found in Matabeleland regions of Zimbabwe, for example Bulawayo which is the second largest city of Zimbabwe. 
The historical Shona and Ndebele relations in the $19^{\text {th }}$ century were far from cordial and it remains a controversial trend among Afro-centric historians. Some point out that the trouble relations between the Ndebele and Shona were exaggerated. "The Ndebele -Shona relations were by no means as colonial as history presented them, (Beach, 1980:108). The controversial and historical Ndebele-Shona relations, compels one to study about the present day Zimbabwe. This study aims to explore the ethnic group's relations in Diaspora (Shona-Ndebele), implement network analysis in the study of relationships, compare if the trouble relations back home can be replicated in Diaspora and also look at the effects of social interactions in Diaspora. Since this might lead to a better imagination and notion of a true reality of the Zimbabwean community as a whole. This paper will avoid narrowing the argument to Ndebele and Shona relations only but will also look at how the other ethnic groups are incorporated.

\section{Literature Review}

There are many historical books written on the Ndebele-Shona relations and other ethnic groups, for instance Kalanga, but little has been done on the analysis of the social networks or relations between the Ndebele and Shona groups of this twenty first century generation. Eurocentric literature presents a non-cordial relationship between the Shona and Ndebele infiltrated by historical enmity and tensions. Bhebe (1973:17) cited in Ndlovu-Gatsheni (2009:46) pointed out that, the orthodox school of thought reduced the Ndebele history to military issues and some political aspects as he highlighted for attention issues such as religion and trade as aspects of Ndebele history. Bhebe exploded the myth that war, conflict and raids were the main landmark of Ndebele -Shona relations. Looking on the pre-colonial Shona-Ndebele relations, history shows that religion and trade were the basis of the relationship, although there were other political conflicts of dominance and rule.

\subsection{Pre-colonial, Ndebele relations with other groups including Shona and Kalanga}

The pre-colonial and colonial relations of the Shona, Ndebele and other Zimbabwean ethnic groups remain a controversial issue. In the $19^{\text {th }}$ century, the Ndebele speaking people were perceived as aggressive fighters and a people with different cultural beliefs from the Shona speaking people. "The construction of Ndebele ethnicity and various categories of origin began through the asymmetric incorporation of dissimilar groupings into a pre-colonial politicoeconomic system and into the Ndebele state", (Broch-Due, 2005: 156). Msindo, (2012:49) is of the view that, some of the Shona groupings, Kalanga and Venda were incorporated into the Ndebele culture.

This means that, some of the non-Ndebele groupings in the land were 'Ndebelelised' depending on their geographical location and the nature of their interactions with the Ndebele.

Msindo (2012:49) further noted that, some Kalanga people accepted Ndebele ethnicity as the only viable option to secure themselves against the raiding system and being Ndebele in the $19^{\text {th }}$ century was about taking up both a new political identity and its associated ethnic citizenship.

The assertion proves that the pre-colonial Ndebele Kingdom incorporated other ethnic groups; however those who identified themselves with the Ndebele became 'Ndebelelised'. The opposite means the same; those who incorporated themselves with the Shona became 'Shonalised'.

It is noteworthy that when the Ndebele crossed the Limpopo form the South, they further disrupted the Tonga settlements south of the Zambezi valley, (Kwashirai 2009:37). The Ndebele Kingdom incorporated other ethnic groups such as the Tonga, Kalanga and San through capture and raids. However, Kwashirai (2009: 37) argues that "the Ndebele settlers created new ways of life, acquitting themselves with and interacting with the subject peoples and adopting some of their customs and values such as ceremonies of propitiating the land, reciprocal socioeconomic and political relations existed among these diverse ethnic groups on the eve of British colonial occupation in 1890".

This means that, the Ndebele people had to adjust to a new environment in order to relate well with the ethnic groups incorporated. These ethnic groups, especially a large number of the Tonga and Kalanga became 'Ndebelelised', embraced a new way of life. Those Shona groups, who happened to live at the periphery of the Ndebele Kingdom, were also incorporated. Today in the Matabeleland province, the Ndebele, Tonga, Kalanga and Nambya co-exist peacefully.

\subsection{The Caste System}

The social structure of the pre-colonial Ndebele kingdom was divided into three classes, namely the ezansi, enhla and hole. "The original Nguni group, (the Khumalo) referred to itself as the abeZansi , meaning 'those from the South', while the Sotho group was known as abeNhla ,'those from the North' and the rest were abeHole or abeLozwi, these being the 
incorporated Shona, Kalanga , Tonga ,Venda ,Nambya groupings", (Malaba and Davis,2007:80). There were inter marriages, of course, trade and economic relations based on economic reasons. However scholars argue that intermarriages were only allowed between abeZansi and abeNhla.

\subsection{Colonial, Shona and Ndebele relations}

De Waal, (1990:89) as cited in Raftopoulos and Savage, (2004:142) argues that, "Portrayals of Shona -Ndebele relationships were manipulated during the colonial era in order to divide and rule". The Eurocentric writers portrayed the relationship among the ethnic groups in Zimbabwe as far from cordial. "The colonially-propagated narrative was that, in the $19^{\text {th }}$ century defenceless Shona people were attacked by the fierce Ndebele warriors coming from the South, who, fleeing the wrath of Shaka Zulu, crossed the Limpopo and proceeded to raid for cattle, women and land. The Eurocentric historiography postulated that raids continued until the Pioneer column arrived in the 1890s and put an end to this oppression", (Raftopoulos and Savage, 2004:142).

The above assertion shows that the coming of British settlers in Zimbabwe, by then, called Southern Rhodesia, paralyzed the existence of ethnic states. Rural-urban migration brought with it a cosmopolitan society and the introduction of mines and factories created another social paradigm.

"In the colonial version, then, the Shona were disorganized weaklings, the Ndebele were mindless militaristic bullies, while the enlightened white settlers and the British South Africa Company (BSAC) brought peace, order and God, (Raftopoulos and Savage, 2004:142).

These assertions remain disputed and unjustified. However one cannot dismiss the fact that the capitalist brought industrialization which transformed the African society into a new socio-political and economic order. English became a second language and a new dispensation of culture was put into order such as education, trade unions, labour unions and political parties.

Nationalism

The emergence of a cosmopolitan society facilitated the working together of the Zimbabweans against the colonial regime.

Sicilia (1999:7) noted that, "from 1896 to 1897, Ndebele and Shona people fought alongside each other for the first time in their history against the colonial rulers".

This means that, during the colonial rule, Zimbabweans found themselves united for one common cause, which was the desire for independence.

"Capitalism began to transform social and economic relations on the land and in the early mine and towns, new forms of social struggles and identities emerged. The emergence of an African identity specific to Southern Rhodesia which is to say a Zimbabwean African National consciousness, as evidenced by the rise of anti-colonial nationalism" ,(Raftopoulos and Mlambo,2008:xix).

All Zimbabweans regardless of the ethnic belonging recognized themselves as Zimbabweans and had one common goal which is to gain independence as preached by political leaders.

The 'nationalizing' of the African elite took an important turn in the mid-1930s culminating in the establishment of the Bantu Congress, the first political party, (Raftopoulos and Mlambo 2008: xix). Later on new political movements emerged such as the Zimbabwe African People's Union (ZAPU) led by Joshua Mqabuko Nkomo and Zimbabwe African National Union (ZANU) with the two merging in 1988 to form ZANU PF, now led by a veteran leader and President Robert Gabriel Mugabe. These revolutionary parties incorporated both Ndebele and Shona who were united for the common cause, the Independence of Zimbabwe.

\subsection{The Post-Colonial Zimbabwe}

Very little has been published about the Ndebele-Shona relations in the post -colonial era. Zimbabwe got its independence in 1980 and from the period of 1980 until today the relations between the two major ethnic groups, Shona and Ndebele have been more of political.

Ndlovu-Gatsheni (2009:21) noted that, "Post-colonial state leadership faced the challenge of constructing a nation -state from people of diverse ethnic, cultural, religious and linguistic background. It had the mammoth task of facilitating a situation where hitherto enemies could co-exist and identity with the new nation-in-the-making".

As aforesaid, Zimbabwe consists of diverse ethnic, cultural, religious and linguistic differences, however it was then the responsibility of the state leadership to build nation into one people regardless of ethnic differences. 
The President of Zimbabwe once said, "Zimbabwe is one entity and shall never be separated into different entities, (Ndlovu-Gatsheni, 2009:28).

Nation building was not an easy task and it continues to be a challenging phase even today. The two major ethnic groups, Ndebele and Shona, with historic antagonism, were left with a challenge of re-uniting and putting aside ethnic differences.

\subsection{Ndebele-Shona relations in Diaspora}

According to Takwana (2006-10-27), "Inter-ethnic differences between Shona and Ndebele people caused the massacres of Ndebele people from 1980 to 1987". He carried out a study on the impact of social interaction on ethnic identity perceptions Shona and Ndebele people of Zimbabwe and perceptions after social interactions in Johannesburg, South Africa. The nature and extent of social interaction were surveyed and sixteen participants from each group were interviewed. His findings were that social interactions have helped in weakening negative ethnic identity perceptions Shona and Ndebele people have to each other. From his findings, a larger number of respondents expressed views which showed support of weakening negative ethnic identity perceptions through social interactions such as intermarriages, street vending association, church interactions and business sharing. He goes on to say that "the impact of that on the existing literature is that the findings support the argument that under certain conditions contact leads to the weakening of prejudices, perceptions or attitudes",( Takwana, 2006).

It is worth mentioning that, social interaction reduced the level of tensions and those residual tensions are becoming extinct. The Zimbabwe Diaspora community tends to be more of tolerant, transformed society and cordial relations to one another is bound to be there due to the level of social interactions. New developments such as intermarriages, church fellowship are some of the factors that weaken the past prejudices and unfriendly relations.

\section{Research Methodology}

\subsection{Participants}

The population consists of 103 respondents among them students, tutors and lecturers at University of Fort Hare, Alice Campus. Some of them have stayed in Diaspora for more than seven years five and four. The least are those who have two years studying at University of Fort Hare.

\subsection{Instruments}

The instrument used in this study was in-depth interviews. Data was analyzed using Network Analysis to analyse the social interactions of the Zimbabweans at University of Fort Hare. However the analysis of data needed a better quantitative and qualitative methodology hence the use of "Social Network Analysis which is the application of the broader field of network science to the study of human relationships and connections. Computer assisted Software such as NodeXL and VUE (Visual Understanding Environment) were also used to analyse the social interactions. 


\section{Findings and Discussion}

\subsection{Visual Understanding Environment (VUE diagram) of The UFH Zim Community}

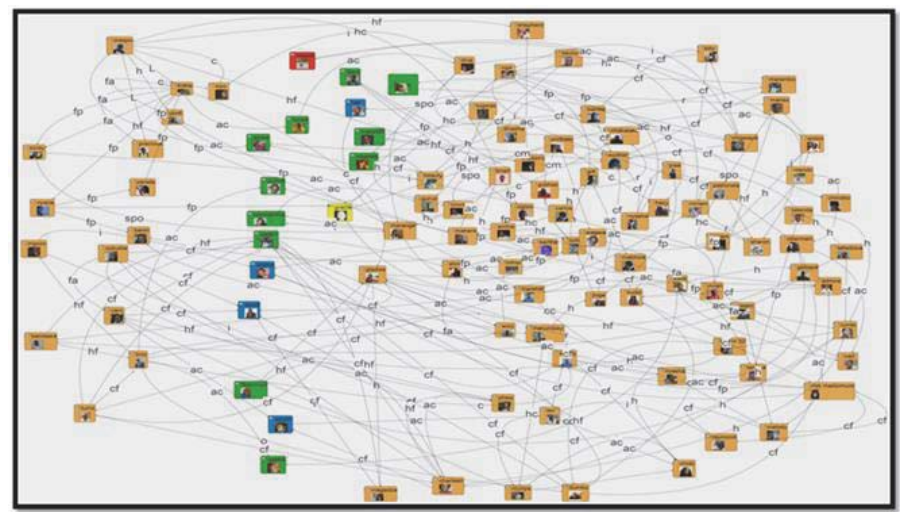

Figure 1: Visual Understanding Environment (VUE diagram) of The UFH Zim Community

$$
\text { (Ndebele Zim) } \underbrace{\text { (Shona Zim) }}_{\text {Centre (green-South African) blue (Nigerians) yellow (Congolese) }}
$$

(Ndebele Zim)

(Shona Zim)

Abbreviations

cf - church interaction ac - academic interactions

$f p$ - drinking and partying $i$ - intimate relationship

$h f$ - hostel interactions $h$ - home based relationship

spo- sporting interactions $L$ - language based relationship

$o$ - Old school friendship $r$ - room based relationship

fa-family

Zim-Zimbabwe (an) c-colleagues

\subsection{NodeXL diagram of University of Fort Hare Zimbabwean Community}

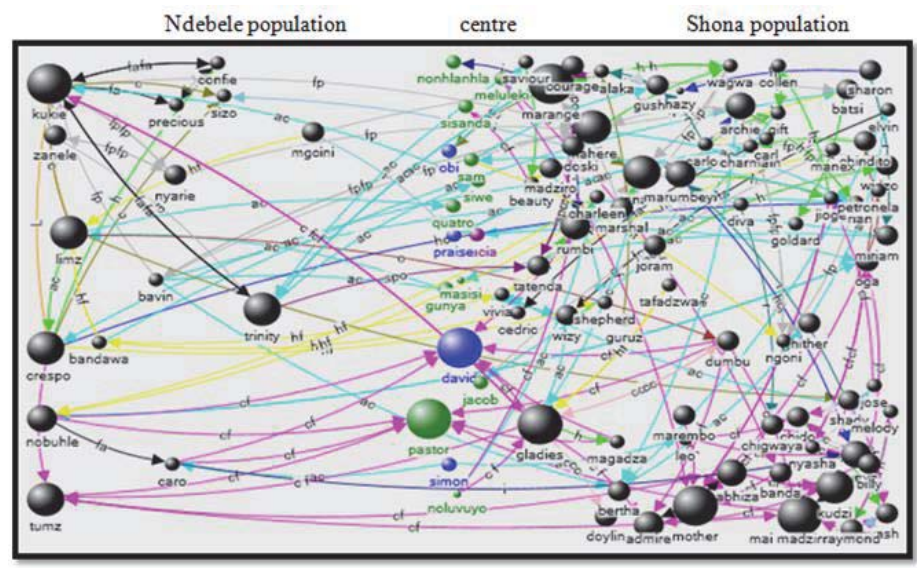

Figure 2: University of Fort Hare Zimbabwean Community

The Shona population is larger than the Ndebele population. This reflects the fact that, on the ground Shona people are a majority. It is also noteworthy that, the visible edges on the diagram highlight types of relational data. The yellow edges show the links between the Ndebele and the Shona as $h f$, hostel based friendship. The pink edges represent the church 
based relationship. The blue edges represent the academic based friendship. Brown edges represent partying and drinking type of a relationship. These are the dominant type of relationships between the Shona and Ndebele found in the diagram above.

\subsection{Calculating graph metrics}

Table 1: Graph Metrics

\begin{tabular}{|c|c|c|c|c|c|c|c|}
\hline Vertex & Degree & $\begin{array}{c}\text { In- } \\
\text { Degree }\end{array}$ & $\begin{array}{l}\text { Out- } \\
\text { Degree }\end{array}$ & $\begin{array}{c}\text { Betweenness } \\
\text { Centrality }\end{array}$ & $\begin{array}{l}\text { Closeness } \\
\text { Centrality }\end{array}$ & $\begin{array}{l}\text { Eigenvector } \\
\text { Centrality }\end{array}$ & $\begin{array}{l}\text { Clustering } \\
\text { Coefficient }\end{array}$ \\
\hline $\begin{array}{c}\text { Respondent } \\
1\end{array}$ & 13 & 5 & 8 & 1819.876 & 0.003 & 0.048 & 0.027 \\
\hline 2 & 3 & 3 & 0 & 328.774 & 0.003 & 0.016 & 0.000 \\
\hline 3 & 3 & 1 & 2 & 12.128 & 0.003 & 0.019 & 0.167 \\
\hline 4 & 1 & 0 & 1 & 0.000 & 0.002 & 0.009 & 0.000 \\
\hline 5 & 7 & 2 & 5 & 639.093 & 0.003 & 0.034 & 0.100 \\
\hline 6 & 1 & 1 & 0 & 0.000 & 0.002 & 0.009 & 0.000 \\
\hline 7 & 5 & 3 & 2 & 650.189 & 0.003 & 0.028 & 0.050 \\
\hline 8 & 5 & 4 & 1 & 471.750 & 0.003 & 0.016 & 0.200 \\
\hline 9 & 5 & 4 & 1 & 112.294 & 0.003 & 0.019 & 0.250 \\
\hline 10 & 10 & 9 & 7 & 1981.209 & 0.003 & 0.061 & 0.091 \\
\hline 11 & 3 & 0 & 3 & 71.441 & 0.003 & 0.014 & 0.167 \\
\hline 12 & 3 & 3 & 0 & 424.152 & 0.003 & 0.020 & 0.167 \\
\hline 13 & 2 & 3 & 2 & 8.786 & 0.003 & 0.022 & 0.333 \\
\hline 14 & 4 & 1 & 3 & 9.467 & 0.003 & 0.020 & 0.667 \\
\hline 15 & 4 & 4 & 4 & 583.338 & 0.003 & 0.023 & 0.067 \\
\hline 16 & 2 & 2 & 3 & 7.405 & 0.003 & 0.021 & 0.333 \\
\hline 17 & 1 & 1 & 1 & 0.000 & 0.003 & 0.016 & 1.000 \\
\hline 18 & 1 & 2 & 1 & 0.000 & 0.003 & 0.016 & 1.000 \\
\hline 19 & 4 & 4 & 2 & 167.353 & 0.003 & 0.031 & 0.350 \\
\hline 20 & 5 & 4 & 4 & 542.782 & 0.003 & 0.023 & 0.200 \\
\hline 21 & 5 & 4 & 3 & 489.861 & 0.003 & 0.028 & 0.233 \\
\hline 22 & 6 & 2 & 4 & 1102.444 & 0.003 & 0.007 & 0.033 \\
\hline 23 & 3 & 3 & 1 & 2.833 & 0.002 & 0.011 & 0.500 \\
\hline 24 & 3 & 1 & 2 & 111.099 & 0.002 & 0.008 & 0.167 \\
\hline 25 & 2 & 3 & 1 & 172.140 & 0.002 & 0.012 & 0.167 \\
\hline 26 & 1 & 1 & 1 & 0.000 & 0.002 & 0.003 & 0.500 \\
\hline 27 & 3 & 3 & 1 & 393.170 & 0.002 & 0.003 & 0.000 \\
\hline 28 & 3 & 2 & 2 & 401.169 & 0.002 & 0.001 & 0.000 \\
\hline 29 & 5 & 4 & 3 & 586.807 & 0.002 & 0.004 & 0.033 \\
\hline 30 & 1 & 0 & 1 & 0.000 & 0.002 & 0.000 & 0.000 \\
\hline 34 & 1 & 1 & 0 & 0.000 & 0.002 & 0.001 & 0.000 \\
\hline 35 & 3 & 1 & 2 & 83.695 & 0.002 & 0.005 & 0.500 \\
\hline 36 & 2 & 1 & 3 & 263.461 & 0.002 & 0.007 & 0.000 \\
\hline 37 & 5 & 2 & 4 & 324.569 & 0.002 & 0.010 & 0.150 \\
\hline 38 & 4 & 2 & 3 & 194.669 & 0.002 & 0.007 & 0.250 \\
\hline 40 & 4 & 2 & 3 & 180.998 & 0.003 & 0.012 & 0.167 \\
\hline 41 & 5 & 3 & 2 & 539.746 & 0.003 & 0.013 & 0.200 \\
\hline 42 & 4 & 2 & 2 & 33.605 & 0.003 & 0.014 & 0.250 \\
\hline 43 & 5 & 3 & 4 & 1688.407 & 0.003 & 0.020 & 0.133 \\
\hline 44 & 4 & 2 & 3 & 394.305 & 0.003 & 0.016 & 0.100 \\
\hline 45 & 4 & 6 & 0 & 760.581 & 0.003 & 0.029 & 0.167 \\
\hline 46 & 2 & 0 & 2 & 34.842 & 0.002 & 0.003 & 0.000 \\
\hline 47 & 4 & 3 & 1 & 169.947 & 0.002 & 0.005 & 0.083 \\
\hline 48 & 3 & 1 & 2 & 24.267 & 0.002 & 0.002 & 0.167 \\
\hline 49 & 5 & 1 & 4 & 814.050 & 0.003 & 0.013 & 0.050 \\
\hline 50 & 4 & 3 & 1 & 151.976 & 0.002 & 0.005 & 0.167 \\
\hline
\end{tabular}




\begin{tabular}{|c|c|c|c|c|c|c|c|}
\hline 51 & 3 & 1 & 2 & 441.365 & 0.003 & 0.004 & 0.000 \\
\hline 52 & 3 & 5 & 1 & 477.990 & 0.003 & 0.022 & 0.067 \\
\hline 53 & 4 & 2 & 2 & 777.701 & 0.002 & 0.001 & 0.000 \\
\hline 54 & 2 & 1 & 1 & 39.633 & 0.002 & 0.000 & 0.000 \\
\hline 55 & 2 & 1 & 1 & 434.097 & 0.002 & 0.001 & 0.000 \\
\hline 56 & 2 & 1 & 3 & 18.760 & 0.002 & 0.011 & 0.167 \\
\hline 57 & 5 & 7 & 0 & 930.014 & 0.002 & 0.002 & 0.071 \\
\hline 58 & 1 & 1 & 2 & 19.256 & 0.002 & 0.010 & 0.333 \\
\hline 59 & 6 & 4 & 5 & 1907.285 & 0.003 & 0.005 & 0.024 \\
\hline 60 & 2 & 1 & 1 & 752.000 & 0.002 & 0.001 & 0.000 \\
\hline 61 & 2 & 1 & 2 & 66.667 & 0.002 & 0.001 & 0.000 \\
\hline 62 & 2 & 0 & 2 & 0.000 & 0.002 & 0.002 & 0.500 \\
\hline 63 & 2 & 2 & 0 & 0.000 & 0.002 & 0.002 & 0.500 \\
\hline 64 & 2 & 1 & 1 & 167.600 & 0.002 & 0.001 & 0.000 \\
\hline 65 & 2 & 2 & 1 & 143.767 & 0.002 & 0.000 & 0.000 \\
\hline 66 & 1 & 1 & 0 & 0.000 & 0.002 & 0.001 & 0.000 \\
\hline 67 & 3 & 2 & 1 & 572.106 & 0.002 & 0.001 & 0.000 \\
\hline 68 & 2 & 1 & 1 & 74.740 & 0.002 & 0.000 & 0.000 \\
\hline 69 & 2 & 1 & 1 & 92.352 & 0.002 & 0.000 & 0.000 \\
\hline 70 & 2 & 2 & 1 & 220.167 & 0.002 & 0.001 & 0.000 \\
\hline 71 & 5 & 3 & 5 & 2113.125 & 0.003 & 0.033 & 0.018 \\
\hline 72 & 2 & 1 & 3 & 861.410 & 0.003 & 0.008 & 0.083 \\
\hline 73 & 2 & 0 & 3 & 491.610 & 0.003 & 0.007 & 0.000 \\
\hline 74 & 1 & 1 & 0 & 0.000 & 0.002 & 0.001 & 0.000 \\
\hline 75 & 3 & 2 & 2 & 526.920 & 0.002 & 0.004 & 0.000 \\
\hline 76 & 3 & 3 & 1 & 279.126 & 0.002 & 0.002 & 0.083 \\
\hline 77 & 1 & 0 & 1 & 0.000 & 0.002 & 0.000 & 0.000 \\
\hline 78 & 2 & 2 & 1 & 194.000 & 0.002 & 0.002 & 0.167 \\
\hline 79 & 1 & 1 & 0 & 0.000 & 0.002 & 0.006 & 0.000 \\
\hline 80 & 1 & 0 & 1 & 0.000 & 0.002 & 0.006 & 0.000 \\
\hline 81 & 3 & 2 & 3 & 177.024 & 0.002 & 0.005 & 0.000 \\
\hline 82 & 3 & 3 & 1 & 42.168 & 0.002 & 0.004 & 0.167 \\
\hline 83 & 2 & 1 & 2 & 73.374 & 0.002 & 0.001 & 0.000 \\
\hline 84 & 1 & 1 & 0 & 0.000 & 0.002 & 0.002 & 0.000 \\
\hline 85 & 5 & 2 & 6 & 1353.577 & 0.003 & 0.040 & 0.071 \\
\hline 86 & 2 & 2 & 1 & 268.871 & 0.002 & 0.001 & 0.167 \\
\hline 87 & 2 & 1 & 1 & 0.000 & 0.002 & 0.000 & 0.500 \\
\hline 88 & 2 & 1 & 1 & 57.333 & 0.002 & 0.002 & 0.000 \\
\hline 89 & 4 & 1 & 3 & 407.951 & 0.003 & 0.010 & 0.000 \\
\hline 90 & 1 & 0 & 1 & 0.000 & 0.002 & 0.000 & 0.000 \\
\hline 91 & 2 & 0 & 2 & 318.819 & 0.002 & 0.004 & 0.000 \\
\hline 92 & 3 & 1 & 2 & 194.879 & 0.002 & 0.007 & 0.000 \\
\hline 93 & 2 & 1 & 1 & 5.333 & 0.002 & 0.003 & 0.000 \\
\hline 94 & 3 & 1 & 2 & 574.000 & 0.002 & 0.000 & 0.000 \\
\hline 95 & 2 & 0 & 2 & 194.000 & 0.002 & 0.000 & 0.000 \\
\hline 96 & 1 & 1 & 0 & 0.000 & 0.001 & 0.000 & 0.000 \\
\hline 97 & 1 & 1 & 0 & 0.000 & 0.001 & 0.000 & 0.000 \\
\hline 98 & 3 & 0 & 3 & 46.024 & 0.002 & 0.002 & 0.333 \\
\hline 99 & 2 & 2 & 0 & 81.056 & 0.002 & 0.008 & 0.000 \\
\hline 100 & 3 & 1 & 2 & 97.303 & 0.002 & 0.006 & 0.167 \\
\hline 101 & 4 & 1 & 6 & 454.195 & 0.003 & 0.033 & 0.200 \\
\hline 102 & 6 & 6 & 0 & 645.723 & 0.003 & 0.026 & 0.100 \\
\hline 103 & 2 & 0 & 2 & 0.000 & 0.002 & 0.000 & 0.500 \\
\hline
\end{tabular}

The Graph metrics above reflect the inter-networks in the NodeXL diagram. The verteces show the respondents of all Zimbabweans interviewed and some of the South Africans, Nigerians and Congolese. Nigerians are the second largest foreigners at University Of Fort Hare and Zimbabweans the first largest group. 


\subsubsection{Degree centrality:}

Those with highest connections include respondent 1 and respondent 10 (13:10). Respondent 1 is Shona and Respondent 10 is Kalanga but identifies herself with the Ndebele. They both interact and also interact with other Shona and Ndebele. It is evident that the Kalangas identify themselves with the Ndebele. Respondent 14, a Ndebele speaking with degree centrality 4 explains herself as a non associate of the Shona because she realised that the Shona are exploitative and wants her to speak their language whilst they do not want to learn hers. Respondent 14 mentioned that,

"the Shona always want to use one language when communicating and that language is Shona".

Her argument was she can not learn speaking Shona now and why bother? Respondent 5 with degree centrality 5 , a Shona speaking, unveils that some of the Ndebeles are friendly but some are not, she cannot speak Ndebele language but does not mind communicating in english. She interacts with the ndebele at church and at school but those she interacts with speak either shona or english. Looking at the instances given above, language is still a barrier of communication and the problem that arises between the Ndebele and Shona are not only political but communication problems and language being a barrier.

\subsubsection{In-degree:}

The number of connections that point inward at a vertex shows the number of people who draw themselves closer to the person or incline. Many in the community have queit a good number of connections pointing inward. The connections pointing inward, show both different variations when Ndebele relate with the Shona and when Shona relates with the Ndebele. For instance, respondent 53, a Shona with 2 inward connections and these are his fellow home boys, coming form Masvingo. These find themselves close to each other because they share a similar home background and know each other very well. Another example is respondent 7, a Zimbabwean Sotho, but identifies himself with the Ndebele, has 3 inward connections, these include his sister based in East London and church friends. Church relationships seem to be of value to him. The instances above narrates that people who become close to a person are important, they are either family, church friends or partyng friends .

\subsubsection{Out-degree}

This includes out-ward connections or links that are directed to other vertices from a vertex. The Gaph metrics exhibit a society that has a lot of connections inward and out-ward. One good example is respondent 71 , a Ndebele speaking with 5 out-ward connections. He described himself as musician who associates not on the basis of language but just for socialisation purposes. Linking with business people and interacting with anyone productive is advantageous to his career. He does not mind interacting with Shona or Ndebele and his socialisation is not limited by language as he describes himself as a multi-lingual person. Another example is respondent 100, Ndebele speaking, with 6 out-ward connections. When asked about his social life, he pointed out that:

"University of Fort Hare is just a place where one makes friends on the basis of academic, partying and other social purposes".

He describes the type of friendship as temporal and does not have a home foundation. When he is back in Zimbabwe, he does not communicate with his University of Fort Hare friends and he does not remember calling them. Associating with Shona or anyone is not a problem to him.

\subsubsection{Betweenness centrality and closeness centrality:}

By definition Betweenness centrality is "a measure of how often a given vertex lies on the shortest path between two other vertices and Closeness centrality takes a different perspective from the network vertices capturing the average distance between a vertex and other vertex in the network", (Hansen et al 2011: 32).

Betweenness centrality determines the level of influence a person has in the society. Communication takes place through various channels and protocols and a person with the highest betweennes centrality, for instance, respondent 1 (1819.876) possesses more links and better access to other people in the community. Communicating with respondent 
102 (South African) would not be difficult if $u$ happen to be associating with respondent 1 because she is connected to the respondent 102. People with very low between's centrality find it difficult to send information to those whom they do not associate with. For example when one wants to send information to the President of Zimbabwe Presidential Scholarship Committee he/she is supposed to be linked to one of the facilitators or the members of the Zimbabwean Presidential Scholarship Committee.

The Zimbabwean Presidential Scholarship Committee is composed of elected representatives who are under the Presidential scholarship. These people are connected academically through this scholarship. Hence, it becomes irrelevant to describe a Zimbabwean Society at the University of Fort Hare without mentioning the role played by the Presidential Scholarship in uniting both the Ndebele and Shona, and other ethnic groups. These students were brought into South Africa by one sponsor and find themselves connected for the same cause as they meet similar academic challenges. The Shona being the majority, of course and other groups find themselves immersed into the Shona cultural and political ideologies. Therefore having more links or connections in the society gives one an advantage, making him or her less dependent and powerful.

Looking at Closeness centrality, one should take note that the greater the length between two vertices the weaker the connection, (Hanneman and Riddle, 2005: 9). Most of total measurement of closeness centrality is (0.002: 0.003). In other words it means that the people are close to each other. More especially the environment, that is campus life, assembles them all in a reachable place, inclined to books and studies they find the common ground of interaction. This shows that, probably every Zimbabwean could be familiar with almost $50 \%$ of other Zimbabweans on campus. Many are familiar with each other but do not regularly socialise.

\subsubsection{Eigenvector centrality}

It introduces the assertion that connecting to some other vertices might be better than connecting to others, which means some connections are valuable and some are not. This brings out the question if connecting with the Ndebele or Shona is valuable or not?

Many students find themselves associating with those they think are helpful regardless of language differences.

"The eigenvector approach is an effort to find the most central actors (i.e. those with the smallest farness from others) in terms of the "global" or "overall" structure of the network, and to pay less attention to patterns that are more "local" ",(Hanneman and Riddle, 2005:8).

The central actors refer to those who are influential and helpful, either financially or academically. On academics, the intelligent and progressive students either Shona or Ndebele amass a lot of friends and their association is based on academic purposes. Also South Africans and Nigerians associate with active Zimbabweans. Academics are the central cause for the students to relinquish ethnic differences and conflicts.

\subsubsection{Clustering Coefficient:}

Hansen (2011:33) says that, "clustering coefficient looks on how connected are my friends?"

The network analysis has proven that students are well connected. Hence, it is possible to find a group of five socializing and well connected to one another especially relations based on partying or drinking. Most of the times the relations are reciprocal, meaning they all interact and all are connected to one another. For example if you look at a group whose friendship is based on partying and academics, respondent $21(0.233)$, respondent $20(0.200)$, respondent 19 (0.350), respondent $23(0.500)$ and respondent $100(0.200)$, their relations are reciprocal, they relate with one another and it must be noted that the first four are Shona and the last one is Ndebele. The Shona dominate in numbers and all of the Shona linked in this group come from Harare and are Karanga by dialect. One of the respondents mentioned that, Shona dialects do not matter anymore to them. They see themselves as Shona rather than considering their dialects and sometimes as town boys, they would not know to which Shona dialect they belong to.

\subsection{Social Interactions of the Shona and Ndebele}

There are three types of people identified, (1) moderate (2) pure Shona (3) pure Ndebele. The 'moderate' are those who can associate with Shona while Ndebele or other language and can associate with Ndebele while Shona or other language. 'Pure Shona' are those who find it hard to associate with the Ndebele and the 'Pure Ndebele' are also those who find hard to associate with the Shona. The 'moderate' in most cases come from inter-marriages, whereby their 
parents might be Shona and Ndebele hence they understand both languages. The fact that they understand both languages gives them an advantage to relate and communicate with all groups. The 'moderate' do not have negative attitudes towards other groups; they do not mind speaking other languages. In most cases the 'moderate' are those born in inter-marriages between the Ndebele and Shona and those who have interacted or stayed with other groups, either Ndebele or Shona. The 'moderate', have been with the Ndebele and have been with the Shona, meaning to say, they have travelled Matabeleland and travelled Mashonaland, in places like Bulawayo and Harare.

'Pure Shona' are brought up in a society where they had no social interaction with the Ndebele. They could have been told or read about the Ndebele, meaning they hold prejudices or having attitudes towards the Ndebele. However their contemporary travelling has forced them to meet and interact with the Ndebele or other languages. For example, University of Fort Hare is a multi-lingual environment. There are factors that influence them to associate and communicate with other groups in English language. The same with the 'pure Ndebele' brought up in places like Tsholotsho in Matabeleland and had never been close to a Shona person. They find it challenging to communicate in Shona; they hardly adapt and remain unfriendly with the Shona. Due to certain conditions their conservative characters change but some of them remain unfriendly and relate better with South Africans rather than the Shona.

It was evident that, other factors that contribute to social interactions among the Zimbabweans are academic; same hostel dwellings, church interactions, among others

\subsection{Factors influencing social interactions}

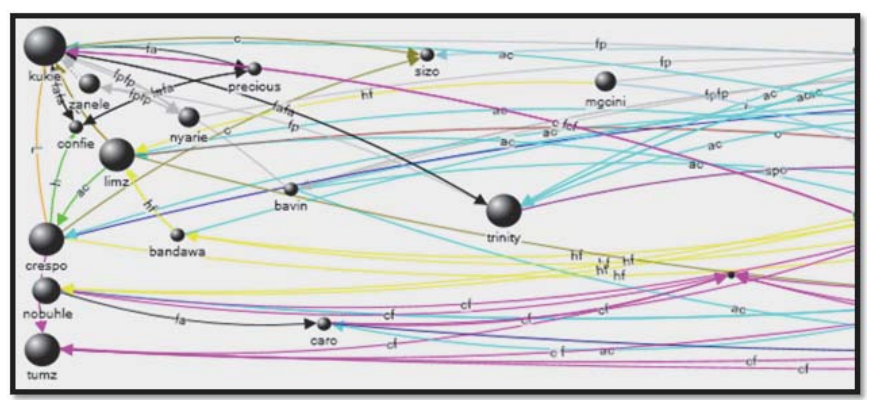

Figure 3: Showing edges linking Ndebele with the Shona ...fp...cf...hf..ac..spo.....i

There are several factors leading to the social interactions among Zimbabwean groups.

In the NodeXL and the VUE diagrams, these conditions have been highlighted as, (cf), (ac),(fp), (h),( i ), (r), ( o), (hf). The Shona and the Ndebele find themselves connected through church activities or interactions (cf), which means, attending one church on campus bring them together thereby building a christian family regardless of the cultural differences. This fact proves that, Christianity is a powerful religious antidote that heals and binds society as one.

Other factors such as academic interactions (ac) means that Zimbabwean Students either Shona or Ndebele interact on academic purposes. They find themselves doing the same programme and eventually have a common goal of studying and appreciating the presence of one another accademically. This means that, some of the relationships are based on academic purposes and nothing else. However some are based on two or more factors including staying together in the same hostel (hf), hostel interactions and doing the same programme (academic interactions). The language of communication becomes a problem if none among them speaks either Shona or Ndebele but as educated people English becomes their language of communication.

In most cases, it is actully very seldom to find two in a group unable to communicate in Shona. It was evident that, most of the Ndebele can speak Shona or understand Shona but most of the Shona cannot understand Ndebele. This resulted in Shona becoming the language in use between the Ndebele and Shona. There are rare cases where you would find a Shona speaking Ndebele except for those who stayed for so long with the Ndebele or Xhosa in Bulawayo or South Africa. Some of the few Ndebele people think relating with the Shona, who can not speak or understand their language is unfair because the Shona want them to communicate in Shona other than learning each other's language. One of the Ndebele repondents said:

"I used to relate with them but I stopped because they do not want to speak or understand my language, they just want me to speak theirs". 
The social relations of the Shona and Ndebele at University of Fort Hare are also influenced by inter- intimate relationships (i). Many Ndebele and Shona students were so open about their relationship status with some Shona young men revealing how much they have been intimately attached to Ndebele and South African ladies. The same goes for he Ndebele young men, who are also in intimate relationships with Shona ladies. However the Shona (boy) and Ndebele (girl) intimate relationships are more than the opposite.

The findings show that the Shona are the majority and out-number the Ndebele hence the Ndebele find themselves immersed into the community. On the other hand 'pure Ndebele' remain conservative to their culture and values as they only date Ndebele or Xhosa South Africans. However, one ought to note that, social interactions compels Zimbabweans to adjust and accept one another, more especially now that they are in diaspora they unite more.

It was also evident that, watching soccer together in television rooms and sporting together (spo) have also increased the levels of interaction meaning that, soccer acts as a uniting factor for Zimbabweans living on campus. A lot of Zimbabwean students prefer watching English premier league to watching Zimbabwe premier leagueresulting in them having same interests which makes them interact. These interactions weaken their cultural differences. Results also show that, drinking and partying (fp) also enhances the level of interactions, which means that, some of the relationships between the Shona and Ndebele are based on drinking and partying on campus. It seems drinking and smoking together induces a common interest which dispels the shadow of enmity.

On the other hand, there are types of relations that can not be found between the Shona and Ndebele, for example, home based relationships ( $h$ ) and family based relationship (fa). These mentinoned can only be found among the Ndebeles alone or the Shonas alone. The problem behind being that, it is unlikely to find a Ndebele and Shona coming from the same home town or rural area. Many Shonas come from Harare, Masvingo, Chiredzi, Kwekwe and Gweru.While few Ndebeles come from Bulawayo, Plumtree, Kariba and other remote parts of Zimbabwe like Hwange and Victoria Falls are so few. Those who come from Plumtree are Kalanga, with a few who are 'pure Ndebele' though they are identified as Ndebele. Many Shona people have a (h) home -based kind of relationship compared to the Ndebele.

The Tonga speaking students are very few in the community and during the interviews, their response was:

"we socialise with everyone but we identify ourselves with Shona students".

The Tonga are found in the regions of Matebeleland and their socialization with the Ndebele has proven them that, in reality the Ndebele ridicule their culture. One said:

"the Ndebeles look down upon us, we relate better with the Shona even though the Shona ridicule our culture as well, they are better".

The Tonga feel segregated in the community although they socialise with the Shona more than the Ndebele. Actually all the Tonga students can speak or understand both Shona and Ndebele. As the minority in the community, they have no choice but to learn the languages of their fellow countrymen. The Ndebeles are said to be more hostile on the Tonga, degrade them and portray them as docile, uncivilised and backward people. In the NodeXL diagrams, Tongas are split into two main camps, either within the Ndebele or the Shona. The reason of splitting the Tonga between two camps is they are very few and they are immersed into either Shona or Ndebele groups.

\section{Concluding Remarks}

It is noteworthy that the trouble ralations between Ndebele and the Shona which exist back home in Zimbabwe are weakened or modified in Diaspora. The level of social interaction is so high at University of Fort Hare. Factors that have been put forward as causing these interactions are, church interactions, hostel interactions, drinking and partying interactions, academic interactions and inter -intimate relationships. It is of great significance to note that living in a diaspora community for more than three or fours years leaves one with no choice but to adjust culturally and socially. Signified from the findings, Shona and Ndebele relate more on academic and church related issues.

However the trouble relations and prejudices remain buried or underwear in diaspora with some of the Ndebele relating more with South Africans than their fellow country people, the Shona. The fact drawn is Ndebele understand Xhosa speaking South Africans more than the Shona language. It seems Ndebele and Xhosa share some common cultural values. In their few numbers the Ndebele remain adjacent to one another .

Other ethnic groups find themselves immersed into either Shona or Ndebele. These include the Tonga, Kalanga, Nambya and Shangani just to mention the identified. The reason being that, they are few and can not separate 
themselves from the majority. The Tonga, Kalanga and Nambya emanate from the provinces of Matebeleland, and interms of language, they are found speaking both Ndebele or Shona. Above all, it is too easy to mistaken a Kalanga as Ndebele because they do not expose themselves much. The Tonga fall between the two camps, either Ndebele or Shona but remain proud of their ethnicity regardless of their minority state. It is important to note that the shona speaking people are a majority in Zimbabwe and the findings of this research replicates that shona groups are the majority in the University of Fort Hare Zimbabwean community. Therefore they out number other Zimbabweans groups, for example the Ndebele.

The Ndebele come from Matebeleland and the Shona from Mashonaland but what unites them all is the concept of being Zimbabweans and being in one schorlaship funding, the Presidential Schorlaship. They have differences, of course, but the differences are weakened by the environmental factors. This conforms to the writings of Broch-Due (2005: 156), who said that "construction of Ndebele ethnicity and various categories of origin began through the asymmetric incorporation of dissimilar groupings into a pre-colonial politico-economic system and into the Ndebele state". The Kalanga relate more and identify themselves with the Ndebele. If they do not tell you that their first language is Kalanga, you can mistake them as Ndebele. The Tonga and Nambya speaking students are very few and can only find none in a group of 20 Zimbabwean students, maybe one in a group of 50 Zimbabwean students. The Tonga and Nambya identify themselves with both Ndebele and Shona, they are not that selective and they can speak both Shona language and Ndebele language without complications. However they relate more with the Ndebele than Shona because they come from the same regions of Matabeleland. In a nutshell, the Ndebele- Shona relations are slowly being transformed form their uneasy historic antagonism. Education and social developments have emancipated Africans from conflicts over ethinic differences.

\section{References}

Beach, D. N 1980. The Shona and Zimbabwe 900-1850: An Outline of Shona History (Gweru, Mambo Press).

Broch-Due, V. 2005. Violence and Belonging. The Quest for Identity in Post -Colonial Africa. Routledge. Canada.

Constitution of Zimbabwe 2013 retrieved from http://www.swradioafrica.com/Documents/Final\%20draft\%20Constitution\%2025\%2 Januar\%202013.pdf Accessed 20/07/2013

Hanneman, R, A and Riddle, M. 2005. Introduction to Social Network Methods. University of California. Riverside CA.

Hansen, D.L. 2011. Analysing Social Media Networks with NodeXL: Insights from a Connected World. Elsevier. Amsterdam.

Kwashirai, V. 2009. Green Colonialism in Zimbabwe 1890-1980. Cambria Press. Amherst NY.

Malaba, M.Z and Davis, G.V. 2007. Zimbabwe Transitions: Essays on Zimbabwean Literature in English. Amsterdam .Newyork.

Msindo, E. 2012. Ethnicity in Zimbabwe: Transformations in Kalanga and Ndebele Societies, 1860-1990. University of Rochester Press. Rochester.

Ndlovu-Gatsheni, S. J. 2009. The Ndebele Nation: Reflections on hegemony, memory and historiography. UNISA Press series. Rozenberg.

Raftopoulos, B and Mlambo, A. 2008. Becoming Zimbabwe: A History from the pre-colonial period to 2008. Weaver Press, Harare.

Raflopoulos, B and Savage, T. 2004. Zimbabwe: Injustice and Political Reconciliat1ion. Institute for Justice and Reconciliation. Cape Town.

Sicilia, O. 1999. There is No Such Thing as a Spirit in the Stone! Misrepresentations of Zimbabwean Stone Sculpture: Anthropological Approach. Boca Raton. Florida

Takwana, M. 2006. The Impact of Social Interactions on Ethnic identity Perceptions: The Case of Shona and Ndebele Migrants Living in Johannesburg. Wits Institutional Repository environment on Dspace.

Zewde, B. 2008. Society, State and Identity in African History. Forum for Social Sciences. Addis Ababa 